\begin{tabular}{ll}
\hline & $\begin{array}{l}\text { Kastamonu Eğitim Dergisi } \\
\text { Kastamonu Education Journal }\end{array}$ \\
$\begin{array}{l}\text { Ocak 2019 Cilt:27 Sayı:1 } \\
\text { kefdergi.kastamonu.edu.tr }\end{array}$ & Başuru Tarihi/Received: 17.12 .2017 \\
& Kabul Tarihi/Accepted: 08.04 .2018 \\
Dol: 10.24106/kefdergi.2474
\end{tabular}

\title{
Beden Eğitimi Öğretmenlerinin Başarı Algılarında Yordayıcı Olarak Akademik İyimserlik, Psikolojik İyi Oluş ve Fiziksel Öz Saygı
}

\section{Academic Optimism, Psychological Well-Being and Physical Self-Esteem as A Predictor of Success Perceptions of Physical Education Teachers}

\section{Öz}

\author{
Aydın KARAÇAM ${ }^{1}$, Atilla PULUR ${ }^{2}$
}

Bu araştırmanın amacı beden eğitimi öğretmenlerinin başarı algıları üzerinde akademik iyimserlik, psikolojik iyi oluş ve fiziksel öz saygı değişkenlerinin yordama güçlerini incelemektir. Araştırma ilişkisel tarama modelinin kullanıldığı betimsel bir çalışmadır. Araştırmanın örneklemi, Ankara ili merkez ilçelerinden seçilen 374 beden eğitimi öğretmeninden oluşmaktadır. Örneklemin belirlenmesinde tabakalı örnekleme tekniği kullanılmıştır. Verilerin çözümlenmesi SPSS 21 ve AMOS programları kullanılarak yapılmıştı. Değişkenler arası ilişkilerin belirlenmesi için Pearson Momentler Çarpımı Korelasyon Katsayısı, beden eğitimi öğretmenlerinin akademik iyimserlik, psikolojik iyi oluş ve fiziksel öz saygılarının başarı algılarının anlamlı yordayıcıları olup olmadığı, değişkenlerin doğrudan ve dolaylı etkileri path analizi ile incelenmiştir. Araştırma sonuçları beden eğitimi öğretmenlerinin başarı algısı, akademik iyimserlik, psikolojik iyi oluş ve fiziksel öz saygı düzeyleri arasında pozitif yönlü ve anlamlı ilişki olduğunu göstermiştir. Ayrıca beden eğitimi öğretmenlerinin başarı algılarını, akademik iyimserlik ve fiziksel öz saygı pozitif yönlü ve doğrudan yordarken, psikolojik iyi oluş akademik iyimserlik üzerinden başarı algısını dolaylı olarak yordamaktadır.

Anahtar Sözcükler: Beden Eğitimi Öğretmeni, Başarı Algısı, Akademik İyimserlik, Psikolojik İyi Oluş, Fiziksel Öz Saygı

\begin{abstract}
The aim of this study is to investigate the predictive values of academic optimism, psychological well-being and physical self-esteem in the success perceptions of physical education teachers. This study is a descriptive study which uses a relational survey model. The sample of the study is comprised of 374 physical education teachers selected from the central counties of Ankara. Stratified sampling technique was used in the determination of the samples. The analysis of the data was done by use of SPSS 21 and AMOS programs. The Pearson Product-Moment Correlation Coefficient for the determination of the relations between the variables, whether the academic optimism, psychological well-being and physical esteem of physical education teachers are rational predictors of success conceptions as well as the direct and indirect effects of the variables were all investigated with path analysis. The results of the study indicated that there is a positive significant relationship between the success perceptions and academic optimism, psychological well-being and physical self-esteem levels of physical education teachers. Besides, while academic optimism and physical self-esteem positively and directly predict the success perceptions of physical education teachers, psychological well-being predicts the success perceptions indirectly by means of academic optimism.
\end{abstract}

Keywords: Physical Education Teacher, Academic Optimism, Psychological Well Being, Success Perception, Physical Self-Esteem

1. İstanbul Aydın Üniversitesi, Spor Bilimleri Fakültesi, İstanbul, Türkiye; https://orcid.org/0000-0001-6509-427X

2. Gazi Üniversitesi, Spor Bilimleri Fakültesi, Türkiye; https://orcid.org/0000-0003-2022-3300

Atıf / Citation: Karaçam, A., \& Pulur, A. (2019). Beden eğitimi öğretmenlerinin başarı algılarında yordayıcı olarak akademik iyimserlik, psikolojik iyi oluş ve fiziksel öz saygı. Kastamonu Education Journal, 27(1), 209-218. doi:10.24106/kefdergi.2474 


\section{Extended Abstract}

\section{Purpose a nd Sig nifica nce}

The purpose of this study is to investigate the predictive values of academic optimism, psychological well-being and physical esteem in the success perceptions of physical education teachers. Differently from the other fields of education, in physical education, "learning the movement and learning by movement" are taken as the basis for instruction (Özmen, 1999; Tamer and Pulur, 2001). For this reason, in addition to the general teacher skills and qualifications, it is can be stated that physical education teachers should also have a good physical body, a stable psychological state and a competence to carry out the necessary academic guidance and instructions (Tamer and Pulur, 2001; Nebioğlu, 2004; Yetim, 2005; Meb, 2015). A physical education teacher should possess the experience of a physiologist in terms of teaching skills, leadership competence of an administrator and preaching skills of a psychologist (Martens, 1998). It can be considered that any physical education teacher having these characteristics can be successful. However, when the relevant literature is reviewed, it can be seen that there is not any holistic study carried out on these characteristics of physical education teachers.

In this context, it is seen that there is a need for a study that can measure the success perceptions and the abovementioned skills and abilities of physical education teachers. The recent studies that have been carried out on the success perceptions of the teachers found out that the success perceptions of the teachers are related to their positive beliefs (Erdoğan, 2013; Sezgin and Erdoğan, 2015). For this purpose, this study focused on academic optimism, psychological well-being and physical self-esteem which are among the positive psychology variables that can affect the success perceptions of physical education teachers.

\section{Method}

As this study sought to determine the relationships between success perception of physical education teachers and academic optimism, psychological well-being and physical self-esteem as well as the direct and indirect predictiveness of the independent variables, the research design was created as relational screening model. The sample of the study was determined by means of stratified sampling model.

Pearson product-moment correlation coefficient was used to determine the relationship between the success perception, academic optimism, psychological well-being and physical self-esteem of physical education teachers. Path analysis technique was implemented within the framework of structural equation modelling for the analysis of direct and indirect predictiveness of independent variables on dependent variables in the study.

\section{Discussion and Result}

The findings of the study reveal that the success perception, academic optimism, psychological well-being and physical self-esteem levels of the teachers have positive and significant relationships. It was seen that the highest relationship was between the success perception and academic well-being. According to the results of the study, when the results of the multiple linear regression analysis related to the predictiveness of success perception are examined, it is seen that academic optimism and physical success are positive and significant predictors of success perceptions. According to the standardized regression coefficients, academic optimism and physical self-esteem are sequenced in the order of importance of predictive variables on success perception. In addition, when the results of multiple linear regression analysis related to the prediction of success perception are examined, it was seen that there is not any significant relationship between psychological well-being and success perception. Accordingly, it can be said that psychological well-being is not a significant predictor of the success perception. Besides, a path analysis was conducted to determine to what extent and direction academic optimism, psychological well-being and physical self-esteem affect the level of success perception of physical education teachers. The direct and indirect impacts of predictive variables were observed on the predicted variables by using the Path analysis. The results of the study indicated that academic optimism and physical self-esteem directly and indirectly predicted the success perceptions. Besides, psychological well-being indirectly and positively predicted the success perception through academic optimism.

\section{Suggestions}

This study is based on academic optimism, psychological well-being and physical self-esteem notions of positive psychology. In this concept, studies that are based on other positive psychology notions which are thought to affect success perception of physical education teachers would make a contribution to literature Positive psychology aims to enhance the life and job quality by focusing on positive senses instead of hitches and problems. It can be said that the individuals having more positive psychological states tend to be healthier, flexible, productive and successful. Further studies in the field of physical education that will be based on the relationship between related concepts of positive psychology and individual and organizational variables will contribute on the analysis of positive psychological dimensions of physical education teachers. Moreover, it can be said that further studies that would be conducted in different schools having different socio-economic level or different educational grades will make a contribution to the literature. In addition, the notions in subject in this study were examined as perceptional in cognitive level. Therefore, practical studies that would be conducted will make a contribution to the literature. 


\section{Giriş}

Beden eğitimi öğretmenleri öğrencilerin bedensel gelişimlerinin yanında duyuşsal, bilişsel ve zihinsel gelişimlerinden de sorumludur (Thomas, 1982; Tamer \& Pulur, 2001; Meb, 2015; Yetim, 2005). Bedensel gelişme ile zihinsel, sosyal ve duygusal gelişme arasında hayati bir bağlant vardır. Çocukların beden sağlığı için yapılan yatırım, aynı zamanda zihinsel, sosyal ve duygusal gelişimi için yapılan bir yatırımdır (Thomas, 1982; Özakpınar, 1987; Yetim, 2005). Bunun yanında Demirhan (2003) beden eğitiminin temel işlev ve amaçlarının; idealler çevresinde, zihinsel gelişim ve duyuşsal dengeyi sağlamak, daha çok üretkenlik sağlayarak bireyi toplumsallaştırmak, bireye yasamda karşılaşacağı sorunları çözebilme becerileri kazandırmak, bireyin doğaya uyumunu sağlamak, bireyin kendini gerçekleştirmesini sağlamak, bireylere beden kültürü kazandırmak ve toplumsal kaynaşmayı sağlamak olduğunu söylemiştir. Bu nedenle beden eğitimi öğretmenleri eğitim sisteminin en önemli parçalarından biridir. Bu bağlamda bakıldığında beden eğitimi öğretmenlerinin mesleklerini başarılı bir şekilde sürdürmeleri öğrencilerin gelişimleri ve başarıları açısından önemli görülmektedir.

Beden eğitiminde, eğitimin diğer alanlarından farklı olarak "hareket öğrenme ve hareket yoluyla öğrenme" esas alınmaktadır (Tamer \& Pulur, 2001; Özmen, 1999). Bu nedenle genel öğretmen yeterliklerinin yanında beden eğitimi öğretmenlerinin fiziksel olarak iyi bir yapıya sahip olmaları, gerekli akademik yönlendirmeleri yapabilecek yetkinliğe ve psikolojik olarak da sağlam bir yapıya sahip olması gerektiği görülmektedir (Tamer \& Pulur, 2001; Meb, 2015; Nebioğlu, 2004; Yetim, 2005). Beden eğitimi öğretmeni öğretme becerilerinde bir fizyoloğun deneyimine, bir idarecinin yönetim liderliğine ve bir psikoloğun öğüt verme becerisine sahip olmalıdır (Martens, 1998). Beden eğitimi öğretmenlerinde bulunması gereken kişilik özellikleri "eleştiriye açık olma, öğrenciyi her konuda anlama, sempatik, samimi ve geniş bakış açısına sahip olma" olarak belirtmiştir (Saçlı, Bulca, Demirhan ve Kangalgil, 2009; Nebioğlu, 2004; Messing 1980; Yetim, 2005). Buradan hareketle bu özellikleri taşıyan beden eğitimi öğretmenlerinin başarılı oldukları düşünülebilir. Ayrıca bu özelliklere sahip olduğunu düşünen beden eğitimi öğretmenleri de kendilerini başarılı olarak algılayabilir. Ancak alan yazın incelendiğinde beden eğitimi öğretmenlerinin başarı algılarını etkileyen değişkenlere yönelik bütünsel bir çalışmaya rastlanamamıştir.

Bu bağlamda beden eğitimi öğretmenlerinin başarı algılarını etkileyebilecek ve belirtilen yeterliliklerini ölçebilecek bir çalışmaya intiyaç olduğu görülmektedir. Son yıllarda öğretmenlerin başarı algılarına yönelik çalışmalarda öğretmenlerin başarı algılarının sahip oldukları pozitif inançlarıyla ilişkili olduğu sonucuna varılmıştır (Erdoğan, 2013; Sezgin \& Erdoğan, 2015). Bu amaçla söz konusu bu araştırmada beden eğitimi öğretmenliğinin özellikleri de göz önüne alınarak başarı algılarını etkileyeceği düşünülen pozitif psikoloji değişkenlerinden akademik iyimserlik, psikolojik iyi oluş ve fiziksel öz saygı üzerinde durulmuştur.

Pozitif psikoloji kavramı, eğitim bilimine psikolojiden kazandırılmış bir kavramdır. Pozitif psikolojinin amacı, yaşamdaki kötü şeyleri düzeltmeye çalışmak yerine yaşam kalitesini arttrmaya çalışmaktır (Seligman, 2002). İnsan yaşamında nelerin doğru gittiğiyle ilgilenen bilimsel bir alan olan pozitif psikolojide son yıllarda öz yeterlik, başarı algısı, psikolojik iyi oluş, performans, iyimserlik, haz ve umut gibi çalışmalara olan ilginin giderek arttğı görülmektedir (Meyers, Woerkom ve Bakker, 2013; Peterson, 2009; Seear ve Brodrick, 2013). Psikolojik durumları pozitif olan bireylerin daha sağlıklı, mutlu, esnek, üretken ve başarılı olacakları söylenebilir (Sezgin \& Erdoğan, 2015).

Başarı önemli ölçüde bu kavramdan ne anlaşıldığına göre değişkenlik göstermektedir (Demirtaş ve Çınar, 2004). Bu bağlamda başarılı öğretmen denilince ne anlaşıldığı önemli görülmektedir (Sezgin \& Erdoğan, 2015). Şeker, Deniz ve Görgen'e (2005) göre alan yeterlikleri, kişilik özellikleri, öğrenmeyi öğretme becerileri, sınıf yönetimi becerileri, planlama, değerlendirme becerileri, teknolojiyi kullanma, iletişim ve rehberlik becerileri gibi yeterliklere sahip öğretmenlerin istendik ve başarılı öğretmenler oldukları düşünülür. Bunun yanında beden eğitimi öğretmeni özelinde ise başarılı öğretmenin fiziksel olarak iyi bir yapıya sahip olması, gerekli akademik yönlendirmeleri yapabilecek yetkinliğe ve psikolojik olarak da sağlam bir yapıya sahip olması gerektiği görülmektedir (Tamer \& Pulur, 2001; Meb, 2015; Martens, 1998; Yetim, 2005; Demirhan, 2003; Thomas, 1982).

İyimserlik kavramı, yeterlik, güven ve akademik önemi bireysel ve örgütsel düzeyde kapsayan bir yapıdır. Akademik iyimserlikle ilgili yapılan araştırmalar okul performansı ve akademik iyimserlik arasında pozitif bir ilişki olduğunu göstermektedir (Hoy \& Tarter, 2011). Öğretmenlerin başarı algıları ile akademik iyimserlikleri arasında da pozitif bir ilişki olduğu görülmüştür (Erdoğan, 2013; Sezgin \& Erdoğan, 2015). Akademik iyimserlik ile öğrenci başarısı (Hoy, Tarter \& Hoy, 2006; Smit \& Hoy, 2007; Hoy, Hoy \& Kurz, 2008) ve okul başarısı (McGuigan \& Hoy, 2006) arasında pozitif yönlü bir ilişki bulunmaktadır. Öğretmenler derslerine iyimser olarak girerse öğrenciler buna pozitif yönde davranış sergileyerek karşılık verir. İyimser eğilimi yüksek öğretmenlerin davranışları da buna paralel olarak etkilenir ve iyimser öğretmen, öğrenme ortamını oluşturarak öğrencilerin başarılı olmasını bekler (Kurz, 2006). 
Psikolojik iyi oluş kavramı, kişinin hayat endişesi ile bireysel ve sosyal ilgileri arasındaki dengeyi kurmak için çabalayacak gücünün olmasıdır. İyi oluş sadece mutlu olmaktan ziyade kişinin gerçek potansiyelini gerçekleştirme çabası olarak da tanımlanmıştır. Psikolojik iyi oluşun faktörleri ise diğerleriyle olumlu ilişkiler, özerklik, çevre hakimiyeti, yaşam amacı, kişisel gelişim ve kendini kabul olarak belirtilmiştir. İnsanların psikolojik olarak kendilerini iyi hissetmeleri onların mutlu olmalarını sağlayacaktır. Bu da doğal olarak tüm potansiyelini olumlu yönde iş çevresine yansıtmasını sağlayacaktır (Ryff, 1989). Bu bağlamda beden eğitimi öğretmeni özelinde bakıldığında psikolojik iyi oluş düzeyleri yüksek olan öğretmenin daha başarılı olacağı düşünülebilir.

Fiziksel öz saygı kavramı, kişinin vücut görünüşüne yönelik olarak öz değerlendirmesidir (Mendelson, Mendelson \& White, 2001; Adams, Turner \& Bucks, 2005). Fiziksel öz saygı konusu daha çok beden algısı konuları içinde incelenmiş ve kişinin bedenini nasıl algıladığı ile ilgili araşttrmalar yapılmıştır (Schilder, 1950; Pehlivan, 2010; Karaçam ve Adıgüzel, 2016). Kılıçarslan (2006) yaptığı çalışmada kişilerin fiziksel benlik algılarındaki artş̧ın iş verimliliğini arttğını belirtmiştir. Pehlivan (2010) yaptığı çalışmada beden eğitimi öğretmen adaylarının fiziksel benlik algılarıyla derse yönelik tutumları arasında pozitif yönde ve anlamlı bir ilişki olduğunu belirtmiştir. Bu bağlamda fiziksel öz saygı beden eğitimi öğretmenlerinin başarılarını olumlu yönde etkileyeceği düşünülebilir.

Yukarıda incelenen araştırmalardan yola çıkıldığında beden eğitimi öğretmenlerinin başarı algılarının önemli olduğu görülmektedir. İncelenen araştırmalara göre beden eğitimi öğretmenlerinin başarı algıları, öğrencilerin başarıları ile ilişkilidir. Başarı algıları öğretmenlerin kendilerini önemli hissetmelerini ve istenilen hedeflere ulaşma yolunda öğrenciler tarafindan takip edilmelerini sağlayacaktır. Bu bağlamda beden eğitimi öğretmenlerinin başarı algıları ile ilişkili olan faktörlerin bilinmesi önemlidir. Bu çalışmada beden eğitimi öğretmenlerinin başarı algılarını etkileyeceği düşünülen pozitif psikoloji kavramlarından, akademik iyimserlik, psikolojik iyi oluş ve fiziksel öz saygı bir bütün olarak ele alınmıştır.

\section{Yöntem}

\section{Model}

Bu araştırmada, beden eğitimi öğretmenlerinin başarı algısı, akademik iyimserlik, psikolojik iyi oluş ve fiziksel öz saygı arasındaki ilişkiler ile bağımsız değişkenlerin doğrudan ve dolaylı yordayıcılıkları belirlenmek istendiğinden araştırma deseni ilişkisel tarama olarak belirlenmiştir. Bu araştırmada beden eğitimi öğretmenlerinin başarı algılarını doğrudan veya dolaylı olarak yordayan faktörlerin belirlenmesi amacıyla yapısal eşitlik modeli kullanılmıştı. Araştırmada yapısal eşitlik modellemesi çerçevesinde değişkenlerle path analizi çalışması yapılmıştır.

\section{Evren ve örneklem}

Araştırmanın evrenini 2015-2016 eğitim-öğretim yılında Ankara ili merkez ilçelerindeki resmi okullarda görev yapan \%59'u (922)erkek, \%41'i kadın toplam 1539 beden eğitimi öğretmeni oluşturmaktadır. Araştırmada tabakalı örneklem yöntemiyle örneklem seçilmiştir. Yüzde 95 güven aralığında 1539 öğretmenden oluşan bir evreni 308 kişinin temsil edebileceği görülmüştür (Büyüköztürk vd., 2010). Örneklem grubundan yüz yüze görüşme yapılarak veriler toplanmıştr. Araştırmaya 238 erkek ve 156 bayan olmak üzere toplam 374 beden eğitimi öğretmeni katılmıştır. Bu öğretmenlerin \%36.4'ü (136) kadın ve \%63.6'sı (238) erkektir. Öğretmenlerin yaş ortalaması 38 ve öğretmenlik kıdemleri 15 yıldır.

\section{Veri Toplama Araçları}

Araştırmada beden eğitimi öğretmenlerinin başarı algılarını belirlemek için Erdoğan (2013) tarafindan geliştirilen "Başarı Algısı Ölçeği", akademik iyimserlik düzeylerini belirlemek için Hoy, Tarter ve Hoy (2006) tarafindan geliştirilen ve Erdoğan (2013) tarafindan Türkçe uyarlaması yapılan "Öğretmen Akademik İyimserlik Ölçeği", psikolojik iyi oluş düzeylerini belirlemek için Ryff (1989) tarafindan geliştirilen ve Akın, Demirci, Yıldız, Gediksiz ve Eroğlu, (2012) tarafindan kısa formu oluşturulan "Psikolojik İyi Oluş Ölçeği" ve fiziksel öz saygılarını ölçmek için Confalonieri, Gatti, lonio ve Traficante (2008) tarafindan geliştirilen ve araştırmacı tarafindan Türkçe uyarlaması yapılan "Fiziksel Saygı Ölçeği" kullanılmıştır.

Başarı Algısı Ölçeği (BAÖ). Beden eğitimi öğretmenlerinin başarı algısını ölçmek amacıyla Erdoğan (2013) tarafindan geliştirilen ölçek kullanılmıştır. Ölçeğin beşli Likert tipi dereceleme biçiminde oluşturulmuş 12 maddesi bulunmaktadır. BAÖ'ye uygulanan AFA ve DFA sonuçlarına göre BAÖ için açıklanan varyansın \%43.11 olduğu görülürken Cronbach's Alpha katsayısı 85 olarak bulunmuştur. Ölçeğe uygulanan AFA sonuçlarına göre ölçek maddelerinin tek faktörde toplandığı görülmüştür. BAÖ’nün tek faktörlü yapısının doğrulanması için yapılan DFA sonuçları tek faktörlü modelin iyilik uyum indekslerinin kabul edilebilir düzeyde olduğunu göstermiştir $\left(\chi^{2} / \mathrm{sd}=1.39, \mathrm{RMSEA}=.057, \mathrm{CFI}=.98, \mathrm{GFI}=.92\right)$.

Yapılan analizlerde BAÖ’ye uygulanan AFA ve DFA sonuçlarına göre ölçekten madde çıkarılmasına gerek duyulma- 
mıştır. BAÖ için açıklanan varyansın \%39.79 olduğu görülürken Cronbach's Alpha katsayısı .84 olarak bulunmuştur. Ölçeğe uygulanan AFA sonuçlarına göre ölçek maddelerinin tek faktörde toplandığı görülmüştür. BAÖ’nün tek faktörlü yapısının doğrulanması için yapılan DFA sonuçları tek faktörlü modelin iyilik uyum indekslerinin kabul edilebilir düzeyde olduğunu göstermiş̧tir ( $\left.\chi^{2} / \mathrm{sd}=3.14, \mathrm{RMSEA}=.078, \mathrm{CFI}=.96, \mathrm{GFI}=.93\right)$.

Akademik lyimserlik Ölçeği (AiÖ). Beden eğitimi öğretmenlerinin akademik iyimserliklerini ölçmek amacıyla Hoy vd. (2006) tarafindan geliştirilen ve Erdoğan (2013) tarafindan Türkçe uyarlaması yapılan "Öğretmen Akademik İyimserlik Ölçeği" kullanıımıştır. AiÖ için KMO değerinin .73, Barlett's (X2) katsayısının $314.04(p<.001)$ ve açıklanan varyansın \%37.29 olduğu görülmektedir. Faktör yüklerinin .49 ile .77 arasında değiştiği görülürken Cronbach's Alpha katsayısı .76 olarak bulunmuştur. Ölçeğe uygulanan AFA sonuçlarına göre ölçek maddelerinin tek faktörde toplandığı görülmüştür.

Yapılan analizler sonucu bu ölçekten 4. 9. ve 11. maddelerin çıkarılmasına karar verilmiş ve kalan 8 madde değerlendirmeye alınmıştr. Aiö için açıklanan varyansın \%42.12 olduğu görülürken Cronbach's Alpha katsayısı .82 olarak bulunmuştur. Ölçeğe uygulanan AFA sonuçlarına göre ölçek maddelerinin tek faktörde toplandığı görülmüştür. Bu sonuçlar Yıldız'ın (2011) ve Erdoğan (2013) araştırma sonuçlarıyla paralellik göstermektedir. Aiö’nün tek faktörlü yapısının doğrulanması için yapılan DFA sonuçları tek faktörlü modelin iyilik uyum indekslerinin kabul edilebilir düzeyde olduğunu göstermiştir $\left(\chi^{2} / \mathrm{sd}=3.40, \mathrm{RMSEA}=.082, \mathrm{CFI}=.96, \mathrm{GFI}=.96\right)$.

Psikolojik Iyi Olma Ölçeği (PiO). psikolojik iyi oluşu ölçmeyi amaçlayan ölçek Ryff (1989) tarafindan geliştirilmiş bir öz-bildirim ölçeğidir. Psikolojik İyi Olma Ölçekleri Kısa Formu (PiOÖ-42) ise Akın v.d. (2012) tarafindan geçerlik ve güvenilirlik çalışması yapılmış PioÖ'nin 42 soruluk kısa formudur. Ölçekte 3, 5, 8, 10,13, 14, 15, 16, 17, 18, 19, 23, 26, 27, 30, 31, 32, 34, 36, 39, 41 numaralı maddeler ters puanlanır. Her biri 7'er sorudan oluşan 6 alt boyutu ile toplam 42 sorudan oluşmaktadır. Ölçeğin geçerlik güvenirlik çalışmalarında kendini kabul için .85, olumlu ilişkiler için .83, özerklik için .88, çevre hâkimiyeti için .81 , yaşam amacı için .82 ve kişisel gelişim için .81 olarak hesaplanmıştır.

Ölçeğin Akın ve Ryff'ın araştırma sonuçlarına göre 6 faktörlü olarak kullanılması uygun bulunmuş ve ölçeğin 6 faktörlü yapısı DFA ile doğrulanarak kullanılmıştır. PiO'nun 6 faktörlü yapısının doğrulanması için yapılan DFA sonuçları modelin iyilik uyum indekslerinin kabul edilebilir düzeyde olduğunu göstermiştir $\left(\chi^{2} / \mathrm{sd}=2.59, \mathrm{RMSEA}=.081, \mathrm{CFI}=.89\right.$, $\mathrm{GFI}=.81)$.

Fiziksel saygı ölçeği (FSÖ). Beden eğitimi öğretmenlerinin fiziksel öz saygılarını ölçmek amacıyla Confalonieri vd. (2008) tarafindan geliştirilen Ergenler ve Yetişkinler için Fiziksel öz saygı Ölçeği araştırmacı tarafindan Türkçeye uyarlanarak kullanılmıştı. Ölçeğin beşli likert tipi dereceleme biçiminde oluşturulmuş 3 boyutta 12 maddesi bulunmaktadır. Ölçekte 2, 4, 6, 8, 10, 12 numaralı maddeler ters puanlanır. FSÖ için açıklanan varyansın \% 57.76 olduğu görülürken ölçeğin geçerlilik güvenirlik çalışmalarında, çekicilik alt boyutunun iç tutarlılığı .73, kilo alt boyutunun iç tutarlılığı .76 ve atf alt boyutunun iç tutarlılığı .64 olarak belirlenmiştir. FSÖ’nun 3 faktörlü yapısının doğrulanması için yapılan DFA sonuçları modelin iyilik uyum indekslerinin kabul edilebilir düzeyde olduğunu göstermiştir $\left(\chi^{2} / \mathrm{sd}=3.69\right.$, RMSEA $=.087$, $\mathrm{CFI}=.89, \mathrm{GFI}=.92$ ).

\section{Verilerin Analizi}

Verilerin analizinde öncelikli olarak veri seti hatalı değer, aykırı değer, normallik ve çoklu bağıntı açısından incelenmiştir. Beden eğitimi öğretmenlerinin başarı algısı, akademik iyimserlik, psikolojik iyi oluş ve fiziksel öz saygı algıları arasındaki ilişkilerin belirlenmesi amacıyla Pearson momentler çarpım korelasyon katsayısı kullanılmıştır. Araştırmada bağımsız değişkenlerin bağımlı değişkenler üzerindeki doğrudan ve dolaylı yordayıcılıklarının incelenmesinde yapısal eşitlik modellemesi çerçevesinde path analizi tekniği kullanılmıştır.

\section{Bulgular}

Beden Eğitimi Öğretmenlerinin Başarı Algısı, Akademik İyimserlik, Psikolojik İyi Oluş ve Fiziksel öz saygı Düzeyleri Arasındaki Iliş̧kiler

Beden eğitimi öğretmenlerinin başarı algısı, akademik iyimserlik, psikolojik iyi oluş ve fiziksel öz saygı düzeyleri arasındaki ilişkiler tablo $1^{\prime}$ de verilmiştir. 
Tablo 1. Beden Eğitimi Öğretmenlerinin Başarı Algısı, Akademik İyimserlik, Psikolojik İyi Oluş ve Fiziksel öz saygı Düzeyleri Arasındaki Ilişkiler $(n=374)$

\begin{tabular}{lcccc}
\hline Değişkenler & 1 & 2 & 3 & 4 \\
\hline 1. Başarı algısı & 1.00 & $.53^{* *}$ & $.26^{* *}$ & $.32^{* *}$ \\
2. Akademik iyimserlik & & 1.00 & $.39^{* *}$ & $.28^{* *}$ \\
3. Psikolojik iyi oluş & & & 1.00 & $.33^{* *}$ \\
4. Fiziksel öz saygı & & & & 1.00 \\
\hline$* * p<.01$ & & & &
\end{tabular}

Beden eğitimi öğretmenlerinin başarı algısı, akademik iyimserlik, psikolojik iyi oluş ve fiziksel öz saygı düzeyleri arasındaki ilişkileri gösteren tablo 1 incelendiğinde, bütün değişkenlerin birbiriyle pozitif yönlü ve anlamlı ilişkili oldukları görülmektedir. En yüksek düzeyde ilişkinin başarı algısı ile akademik iyimserlik arasında olduğu $(r=.53, p=.00)$, en düşük düzeyde ilişkinin başarı algısıyla psikolojik iyi oluş arasında $(r=.26, p=.00)$ olduğu görülmektedir.

Beden Eğitimi Öğretmenlerinin Başarı Algılarında Yordayıcı Olarak Akademik İyimserlik, Psikolojik İyi Oluş ve Fiziksel öz saygı

Beden eğitimi öğretmenlerinin başarı algılarını psikolojik iyi oluş, akademik iyimserlik ve fiziksel öz saygının hangi düzeyde ve yönde yordadığını tespit etmek amacıyla path analizi yapılmıştır. Path analizi kullanılarak yordayıcı değişkenlerin yordanan değişkenler üzerindeki doğrudan ve dolaylı etkileri gözlenmiştir. Bu araştırmada modelin uyumuna ilişkin hesaplanan uyum indeksleri Tablo 2'de gösterilmektedir.

Tablo 2. Modele îlişkin Uyum İndeksleri

\begin{tabular}{ccccccccc}
\hline$c^{2}$ & $\mathrm{sd}$ & $\left(\mathrm{c}^{2} / \mathrm{sd}\right)$ & RMSEA & CFI & NFI & GFI & AGFI & RMR \\
\hline 107.76 & 42 & 2.57 & .06 & .95 & .92 & .95 & .92 & 01 \\
\hline
\end{tabular}

Bu araştrmada modelin uyumuna ilişkin hesaplanan uyum indeksleri modelin verilerle iyi uyum gösterdiği yönün$\operatorname{dedir}\left(\mathrm{X}^{2} / \mathrm{sd}=2.57<5, \mathrm{RMSEA}=.06, \mathrm{CFI}=.95, \mathrm{NFI}=.92, \mathrm{GFI}=.95, \mathrm{AGFI}=.95, \mathrm{RMR}=.01\right)$.

Beden eğitimi öğretmenlerinin başarı algılarını psikolojik iyi oluş, akademik iyimserlik ve fiziksel öz saygının hangi düzeyde ve yönde etkilediğine ilişkin standartlaştııımış path katsayıları Şekil 1'de verilmiştir.

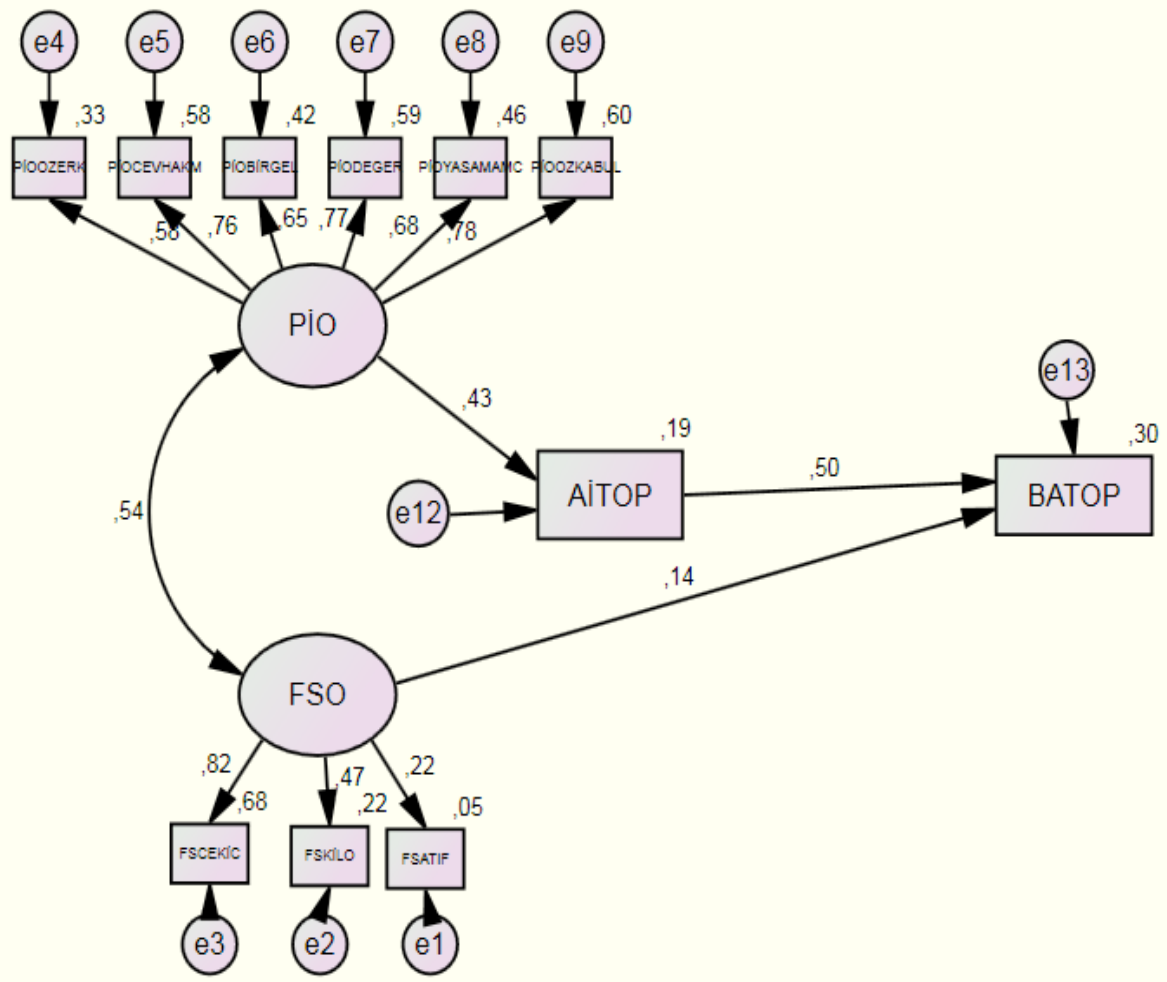

Şekil 1. Standartlaştııımış path katsayıları( BATOP: Başarı algıSı, AiTOP: Akademik iyimserlik, FSO: Fiziksel öz saygı, Pio: Psikolojik iyi oluş) 
Bağımsız değişkenlerin başarı algısı ve akademik iyimserlik üzerindeki doğrudan etkileri Tablo 3'de verilmiştir.

Tablo 3. Bağımsız Değişkenlerin Başarı Algısı Üzerindeki Doğrudan Etkileri

\begin{tabular}{|c|c|c|c|c|c|c|}
\hline $\begin{array}{l}\text { Bağımlı } \\
\text { Değişken }\end{array}$ & Etki & Bağımsız Değişken & $\begin{array}{c}\text { Standardize } \\
\text { Tahmin (Estimate) }\end{array}$ & $\begin{array}{l}\text { Standart } \\
\text { Hata (SE) }\end{array}$ & $\begin{array}{c}\text { Kritik } \\
\text { Oran (CR) }\end{array}$ & $\begin{array}{l}\text { Anlamlılık } \\
\text { Değeri (p) }\end{array}$ \\
\hline \multirow{3}{*}{ Başarı algısı } & $\beta$ & Akademik İyimserlik & .50 & .06 & 11.07 & $.001 * * *$ \\
\hline & $ß$ & Psikolojik iyi oluş & - & - & - & - \\
\hline & $ß$ & Fiziksel öz saygı & .14 & .55 & 2.21 & $.02 *$ \\
\hline \multirow{2}{*}{$\begin{array}{l}\text { Akademik } \\
\text { iyimserlik }\end{array}$} & $\beta$ & Psikolojik iyi oluş & .43 & .09 & 7.09 & $.001 * * *$ \\
\hline & ß & Fiziksel öz saygı & - & - & - & - \\
\hline
\end{tabular}

Tablo 3'deki standartlaştırılmış path katsayıları, başarı algısını akademik iyimserlik $(\beta=.50)$ ve fiziksel öz saygının ( $\beta$ $=.14)$ anlamlı şekilde yordadığını göstermektedir. Öğretmenlerin akademik iyimserliklerini ise psikolojik iyi oluşun ( $\beta=$ .43) anlamlı şekilde yordadığı görülmektedir.

Bağımsız değişkenlerin başarı algısı üzerindeki doğrudan, dolaylı ve toplam etkileri Tablo 4'de gösterilmiştir.

Tablo 4. Bağımsız Değişkenlerin başarı algısı Üzerindeki Doğrudan, Dolaylı ve Toplam Etkileri

\begin{tabular}{lccc}
\hline \multirow{2}{*}{ Değişkenler } & \multicolumn{3}{c}{ Etkiler* } \\
\cline { 2 - 4 } & Doğrudan & Dolaylı & Toplam \\
\hline Akademik İyimserlik & .50 & - & .50 \\
Psikolojik iyi oluş & - & .22 & .22 \\
Fiziksel öz saygı & .14 & - & .14 \\
\hline \multicolumn{2}{c}{ * Standartlaştrıımıs path katsayıları }
\end{tabular}

Tablo 4'e göre akademik iyimserlik $(\beta=.50)$ ve Fiziksel öz saygı $(\beta=.14)$ başarı algısını doğrudan etkilemektedir. Psikolojik iyi oluş ise başarı algısını akademik iyimserlik üzerinden $(\beta=.22)$ dolaylı olarak etkilemektedir.

\section{Tartışma}

Araştırmanın bulguları beden eğitimi öğretmenlerinin başarı algısı, akademik iyimserlik, psikolojik iyi oluş ve fiziksel öz saygı düzeylerinin birbiriyle pozitif yönlü ve anlamlı ilişkili olduğunu ortaya koymaktadır. En yüksek düzeyde ilişkinin başarı algısı ile akademik iyimserlik arasında olduğu görülmüştür. Konuyla ilgili araştrmalar incelendiğinde öğretmenlerin başarı algısı ile akademik iyimserlikleri arasında pozitif yönlü anlamlı ilişki olduğu görülmektedir (Erdoğan, 2013; Sezgin \& Erdoğan 2015). Erdoğan (2013) yaptı̆ı̆ çalışmada bu araştırmanın bulgusuna paralel olarak en yüksek düzeyde ilişkinin başarı algısı ile akademik iyimserlik arasında olduğunu belirtmiştir. Buradan hareketle beden eğitimi öğretmenlerinin başarı algısı ile akademik iyimserlik arasındaki ilişki yönünden araştırma sonuçlarının daha önce yapılmış araştırma sonuçları ile tutarlıık gösterdiği söylenebilir. Bu bulgular beden eğitimi öğretmenlerinin akademik iyimserlik düzeyleri arttkça başarı algısı düzeylerinin de arttı̆ını göstermektedir.

Araştırmanın bulgularına göre başarı algısı ile psikolojik iyi oluş arasında pozitif yönlü ve anlamlı bir ilişki vardır. Araştrrmanın paralelinde Damasio, Silva, Melo ve Aquino (2010) ve Gil-Monte vd. (2011) tarafindan yapılan araştırmalarda öğretmenlerin sosyal ve bireysel başarılarını etkileyen önleyici ve koruyucu stratejiler incelenmiş psikolojik iyi oluş seviyesi düşük olan öğretmenlerde iş veriminin düşebileceği bu durumun da direkt olarak eğitim kalitesini ve öğretmen başarısını etkileyeceğini belirtmiştir. Bu bulgular beden eğitimi öğretmenlerinin psikolojik iyi oluş düzeyleri arttkça başarı algısı düzeylerinin de artabileceğini göstermektedir.

Araştırmanın bulgularına göre psikolojik iyi oluş ile fiziksel öz saygı arasında pozitif yönlü ve anlamlı bir ilişki bulunmuştur. Edwards vd. (2004) spor ve egzersiz yapan bireylerde psikolojik iyi oluş ve fiziksel öz saygı üzerine yapılan çalışmanın bulguları ile çalışmamızın bulguları paralellik göstermektedir. Ayrıca Dotse ve Asumeng (2015) Afrika kökenlilerin fiziksel öz saygı düzeyleri ile psikolojik iyi oluşları arasındaki ilişkiyi belirlemek için yaptıkları çalışmada, fiziksel öz saygı ile psikolojik iyi oluş arasında çalışmamızı destekler şekilde pozitif yönde anlamlı bir ilişki bulmuşlardır. Bu bulgular beden eğitimi öğretmenlerinin psikolojik iyi oluş puanı arttkça fiziksel öz saygı düzeylerinin de arttğını göstermektedir.

Araştırmanın bulgularına göre fiziksel öz saygı ile başarı algısı arasında pozitif yönlü anlamlı bir ilişki vardır. Fiziksel öz saygı düzeyi yükseldikçe başarı algısı düzeyi de artmaktadır. Koparan vd. (2010) beden eğitimi öğretmenleri üzerine 
yaptığı araştırmada çalışmamızın parelelinde sonuçlara ulaşmışlardır. Bu bulgular beden eğitimi öğretmenlerinin fiziksel öz saygı düzeyleri arttkç̧a başarı algısı düzeylerinin de arttğını göstermektedir.

Araştırmanın bulgularına göre beden eğitimi öğretmenlerinin psikolojik iyi oluş düzeyleriyle akademik iyimserlikleri arasında pozitif yönlü ve anlamlı bir ilişki vardır. Çalışmamızın paralelinde Rile vd. (2015) tarafindan akademik personelin psikolojik iyi oluş ve akademik iyimserlikleri üzerine yapılan çalışmada, psikolojik iyi oluş ile akademik iyimserlik arasında yüksek düzeyde anlamlı bir ilişkinin olduğunu bulmuşlardır. Bu bulgular dikkate alındığında beden eğitimi öğretmenlerinin psikolojik iyi oluş düzeyi arttkça akademik iyimserlik düzeylerinin de arttğını görülmektedir.

Araştırma kapsamında beden eğitimi öğretmenlerinin başarı algısı düzeylerini, akademik iyimserlik, psikolojik iyi oluş ve fiziksel öz saygının hangi düzeyde ve yönde etkilediğini tespit etmek amacıyla Path analizi yapılmıştr. Path analizi kullanılarak yordayıcı değişkenlerin yordanan değişkenler üzerindeki doğrudan ve dolaylı etkileri gözlenmiştir. Araştırma sonuçları akademik iyimserlik ve fiziksel öz saygının başarı algısı üzerinde doğrudan ve pozitif yönlü yordadığını göstermektedir. Bunun yanında psikolojik iyi oluşun ise akademik iyimserlik üzerinden başarı algısını dolaylı ve pozitif yönde yordadığını göstermektedir. Yapılan bazı çalışmalarda araştırmayı destekler nitelikte akademik iyimserliğin başarı algısını pozitif yönde ve doğrudan etkilediği sonucuna ulaşıımıştır (Erdoğan 2013; Hoy vd., 2006; McGuigan \& Hoy, 2007; Sezgin \& Erdoğan 2015; Smith \& Hoy, 2007). Psikolojik iyi oluşun başarı algısını doğrudan yordamaması ve akademik iyimserlik üzerinden yordaması, fiziksel öz saygının ise akademik iyimserlik üzerinden değil de doğrudan başarı algısını yordaması beden eğitimi öğretmenlerinin başarı algılarının daha çok fiziksel öz saygılarından etkilendiği şeklinde yorumlanabilir. Ancak detaylı literatür taraması yapılmasına rağmen beden eğitimi öğretmenlerinin başarı algılarının yordayıcılarıyla ilgili bütüncül bir çalışmaya rastlanamamıştı. Araştırmanın bu özelliğiyle alana katkı sağlayacağı düşünülmektedir. Öğretmenlerin iş performansında, başarısında ve eğitimin nihai hedefi olan öğrenci başarısında öğretmenlerin başarı algısı son derece önemlidir (Bandura, 1977, 1993; Judge \& Bono, 2001; Mills vd., 2007; Zeldin vd., 2008). Buradan hareketle araştırmanın bulguları incelendiğinde beden eğitimi öğretmenlerinin akademik iyimserlik, psikolojik iyi oluş ve fiziksel öz saygı düzeylerini artıracak okul temelli uygulamaların yapılması öğrenci başarısı ve eğitimde kalitenin artırılması bağlamında önemsenmesi gerektiği söylenebilir.

\section{Öneriler}

- Bu araştırmada pozitif psikoloji kavramlarından akademik iyimserlik, psikolojik iyi oluş ve fiziksel öz saygı konu edilmiştir. Beden eğitimi öğretmenlerinin başarı algılarını etkileyebileceği düşünülen diğer pozitif psikoloji terimlerini konu alan araştırmaların alan yazına katkı sağlayacağı düşünülebilir.

- Farklı sosyo-ekonomik düzeylerdeki okullarda veya farklı eğitim kademelerinde yapılacak araştırmaların da alan yazına katkıda bulunacağı söylenebilir.

- Bu araştırmada söz konusu bu kavramlar bilişsel düzeyde algısal olarak ele alınmıştr. Yapılacak uygulamaya dönük araştırmaların alan yazına katkı sağlayacağı söylenebilir.

\section{Kaynaklar}

Adams, G., Turner, H., \& Bucks, R. (2005). The experience of body dissatisfaction in men. Body Image, 2(3), 271-283.

Akın, A., Demirci, İ., Yildiz, E., Gediksiz, E., \& Eroglu, N. (2012, May). The short form of the scales of psychological well-being (SPWB-42): The validity and reliability of the Turkish version. Paper presented at the International Counseling and Education Conference, i̇stanbul.

Bandura, A. (1977). Self-efficacy: Toward a unifying theory of behavioral change. Psychological Review, 84(2),191-215.

Byrne, B. M. (1998). Structural equation modeling with LISREL, PRELIS, and SIMPLIS: Basic concepts, applications, and programming. Mahwah, NJ: Lawrence Erlbaum Associates.

Confalonieri, E., Gatti, E., Ionio, C., \& Traficante, D. (2008). Body esteem scale: A validation on Italian adolescents. TPM-Testing, Psychometrics, Methodology in Applied Psychology, 15(3), 153-165.

Damásio, B. F., Melo, R. L. P. D., \& Silva, J. P. D. (2013). Meaning in life, psychological well-being and quality of life in teachers. Paidéia (Ribeirão Preto), 23(54), 73-82.

Demirhan, G.(2003). Beden eğitimi öğretmenlerinin beden eğitimi ve spora ilişkin felsefi görüşleri. Spor Bilimleri Dergisi Hacettepe Üniversitesi, 14(2), 43-44.

Demirtaş, H., \& Çınar, ì. (2004, Temmuz). Yönetici, öğretmen, veli ve öğrencilerin başarı algısı ve eğitime ilişkin görüşleri. 13. Ulusal Eğitim Bilimleri Kurultayı'nda sunulan bildiri, Malatya.

Dotse, J. E., \& Asumeng, M. (2014). Relationship between body ımage satisfaction and psychological well-being: the ımpact of africentric Values.Journal of Social Science Studies, 2(1), 320.

Edwards, D. J., Edwards, S. D., \& Basson, C. J. (2004). Psychological well-being and physical self-esteem in sport and exercise. International Journal of Mental Health Promotion, 6(1), 25-32. 
Erdoğan, O. (2013). ilköğretim öğretmenlerinin öz yeterlilik ve başarı algılarında yordayıcı olarak akademik iyimserlik, umut ve mesleki haz. Yayımlanmamış yüksek lisans tezi. Gazi Üniversitesi, Eğitim Bilimleri Enstitüsü, Ankara.

Gil-Monte, P. R., Carlotto, M. S., \& Gonçalves Câmara, S. (2011). Prevalence of burnout in a sample of Brazilian teachers. The European Journal of Psychiatry, 25(4), 205-212.

Hoy, W. K., Tarter, C. J., \& Hoy, A. W. (2006). Academic optimism of schools: A force for student achievement. American Educational Research Journal, 43(3), 425-446.

Hoy, A. W., Hoy, W. K., \& Kurz, N. M. (2008). Teacher's academic optimism: The development and test of a new construct. Teaching and Teacher Education, 24(1), 821-835.

Hoy, W. K., \& Tarter, C. J. (2011). Positive psychology and educational administration: An optimistic research agenda. Educational Administration Quarterly, 47(1), 427- 447.

Judge, T. A., \& Bono, J. E. (2001). Relationship of core self-evaluations traits-self-esteem, generalized self-efficacy, locus of control, and emotional stability - with job satisfaction and job performance: A meta-analysis. Journal of Applied Psychology, 86(1), 80-92.

Jöreskog, K. G., \& Sörbom, D. (1993). LISREL 8: Structurel equation modeling with the SIMPLIS command language. Lincolnwood, USA: Scientific Software International.

Karaçam, A , Adıgüzel, N . (2016). Beden eğitimi öğretmenlerinin fiziksel saygı düzeylerinin incelenmesi. Gaziantep Üniversitesi Spor Bilimleri Dergisi, 1 (2), 62-74.

Kılıçarslan, E. (2006). Beden eğitimi öğretmenleri ile diğer branşların fiziksel benlik algılarının karşılaştırılması:(Kdz. Ereğli Örneği). Yayımlanmamış yüksek Lisans Tezi, Sakarya Üniversitesi, Sosyal Bilimler Enstitüsü.

Koparan, S., Kuter, F. Ö., \& Korkmaz, N. H. (2010). The evaluation of the self efficacy perception and social physique anxiety of the physıcal education and sports teacher. Sport Sciences, 5(4), 286-293.

Kurz, N. M. (2006). The relationship between teachers' sense of academic optimism and commitment to the profession (Unpublished doctoral dissertation). University of Ohio State, USA.

Martens, R. (1998). Başarılı Antrenörlük (T. Büyükonat, Çev.). İstanbul: Beyaz.

McGuigan, L., \& Hoy, W. K. (2006). Principal leadership: Creating a culture of academic optimism to improve achievement for all students. Leadership and Policy in Schools, 5, 1-27.

Mendelson, B. K., Mendelson, M. J., \& White, D. R. (2001). Body-esteem scale for adolescents and adults. Journal of personality assessment, 76(1), 90-106.

Messıng, M.(1980), Der gute und der schlechte Lehrer aus Schülersichr, Bartel\&Wernitz Verlag, Berlin.

Meyers, M. C., Woerkom, M., \& Bakker, A. B. (2013). The added value of the positive: A literature review ofpositive psychology interventions in organizations. European Journal of Work and Organizational Psychology, 22(5), 618-362.

Milli Eğitim Bakanlığı (2015). Beden eğitimi öğretmenleri özel alan yeterlilikleri. <http://otmg.meb.gov.tr/belgeler/ogretmen_yeterlikleri_kitabi/\%C3\%96\%C4\%9Fretmen_Yeterlikleri_Kitab\%C4\%B1_beden_e\%C4\%9Fitimi_\%C3\%B6\%C4\%9Fretmeni_\%C3\%B6zel_alan_ yeterlikleri_ilk\%C3\%B6\%C4\%9Fretim_par\%C3\%A7a_14.pdf > (2015, Mart 20) sayfasından erişilmiştir.

Mills, N., Pajares, F., \& Heron, C. (2007). SES of college intermediate French students: Relation to achievement and motivation. Language Learning, 57(3), 417-442.

Nebioğlu, D. (2004). Beden Eğitimi Dersi Genel Esasları Planlaması. Ankara: Alp Yayıncılık.

Özakpınar, Y. (1987). Psikolojinin temel mefhumları. Konya: Selçuk Üniversitesi Yayınları.

Özmen, Ö.(1999),Çağdas Sporda Eğitim Üçgeni. (7. Baskı).Ankara: Bağırgan Yayım Evi.

Pehlivan, Z. (2010). Beden eğitimi öğretmen adaylarının fiziksel benlik algıları ve öğretmenlik mesleğine yönelik tutumlarının analizi. Eğitim ve Bilim, 35(156).

Peterson, C. (2009). Positive psychology. Reclaiming Children and Youth, 18(2), 3-7.

Rile, L. G., Tan, N. L., Salazar, N. J., \& Perez, A. G. (2015). Expat University Professors' State of Psychological Well-being and Academic Optimism towards University Task in UAE. Systemics, Cybernetics and Informatics, 13(3), 28-33.

Ryff, C. D. (1989). Happiness is everything, or is it? Explorations on the meaning of psychological well-being. Journal of personality and social psychology, 57(6), 1069.

Saçlı, F., Bulca, Y., Demirhan, G., \& Kangalgil, M. (2009). Beden eğitimi öğretmenlerinin kişisel nitelikleri. Spor Bilimleri Dergisi: Hacettepe Üniversitesi, 20(4), 145-151.

Seear, K. H., \& Vella-Brodrick, D. A. (2013). Efficacy of positive psychology interventions to increase well-being: Examining the role of dispositional-mindfulness. Social Indicators Research, 114, 1125-1141.

Seligman, M. E. P. (2002). Positive psychology, positive prevention, and positive therapy. Handbook of positive psychology, 2, 3-12.

Sezgin, F., \& Erdogan, O. (2015). Academic optimism, hope and zest for work as predictors of teacher self-efficacy and perceived success. Educational Sciences: Theory \& Practice, 15(1), 7-19.

Schilder, P. (1950). The Image and Appearance of the Human Body New York: Int. J. Univ. Press. 
Smith, P. A., \& Hoy, W. K. (2007). Academic optimism and student achievement in urban elementary schools. Journal of Educational Administration, 45(1), 556-568.

Şeker, H., Deniz, S., \& Görgen, İ. (2005). Tezsiz yüksek lisans öğretmen adaylarının öğretmenlik yeterlikleri üzerine değerlendirmeleri. Kuram ve Uygulamada Eğitim Yönetimi, 42, 237-253.

Tamer, K., \& Pulur, A. (2001). Beden Eğitimi Ve Sporda Öğretim Yöntemleri. Ankara: Ada.

Thomas, S. \& Coral, L. A. (1982). Negligence And The Physical Education Teacher. Legal Procedures And Guideliens Physical Educator. USA. Yetim, A. (2005), Sosyoloji ve Spor. İstanbul: Morpa Kültür Yayınları.

Yıldız, G. (2011). Akademik iyimserlik ölçeğinin Türkçeye uyarlanabilirliğinin incelenmesi. Yayımlanmamış yüksek lisans tezi, Gazi Üniversitesi, Ankara.

Zeldin, A. L., Britner, S. L., \& Pajares, F. (2008). A comparative study of the selfefficacy beliefs of successful men and women in mathematics, science, and technology careers. Journal of Research in Science Teaching, 45(9), 1036-1058. 